\title{
Control of Growth and Expression of Differentiated Functions of Mature Hepatocytes in Primary Culture
}

\author{
Toshikazu Nakamura and Akira Ichihara \\ Institute for Enzyme Research, School of Medicine, University of Tokushima, \\ Tokushima 770, Japan
}

\begin{abstract}
Since methods to disperse and culture hepatocytes were developed 15 years ago, numerous investigations have shown that primary cultures of mature hepatocytes retain most liver functions and respond as well to various hormones as those in vivo. Thus they are the most suitable system in vitro for studies on the liver. Moreover, recently it was found that differentiated hepatocytes in culture can grow under certain conditions and that this growth is regulated not only by several hormones, such as insulin, epidermal growth factor and serum growth factor, but also by a cell membrane factor and proteins in the environmental matrix through cell contact.

This article describes the biochemical characterization of regulatory factors for hepatocyte growth and functions and their reciprocal expression. The mechanisms of liver regeneration, differentiation and carcinogenesis and the importance of the tissue architecture for these events are discussed mainly on the basis of our findings.
\end{abstract}

\section{Introduction}

Great efforts have been made over many years to establish conditions for culture of hepatocytes without loss of their diverse liver functions, since so called "established lines of liver cells" do not show appreciable liver functions or respond to hormones (8).

Of the six types of cells found in the liver (parenchymal hepatocytes, bile canalicular cells, Kupffer cells, Ito cells, endothelial cells and fibroblasts), parenchymal cells are responsible for most liver functions. Parenchymal hepatocytes also constitute about $70 \%$ of the total cell population in liver. Therefore, the first step in culture of functional hepatocytes was to isolate these parenchymal cells free from other cell types. This was achieved by Berry and Friend in 1969 by perfusion of the liver with collagenase (1) and their method was later improved by Seglen (34). Thus hepatocytes with various functions became available in high yield as an almost pure population.

For use of these cells in studies on liver functions, the next step was to find culture conditions in which they maintain their hormonal responses for a relatively long

Abbreviations used: WE, Williams medium E; EGF, epidermal growth factor; cis-OH-Pro, cishydroxyproline; PDGF, platelet derived growth factor; HTP, hepatotropin; KD, kilodalton; TAT, tyrosine amino transferase; SDH, serine dehydratase; TO, tryptophan 2,3-dioxygenase; G6PD, glucose-6-phosphate-dehydrogenase; ME, malic enzyme; MEM, minimal essential medium; CSM, cell surface modulator. 


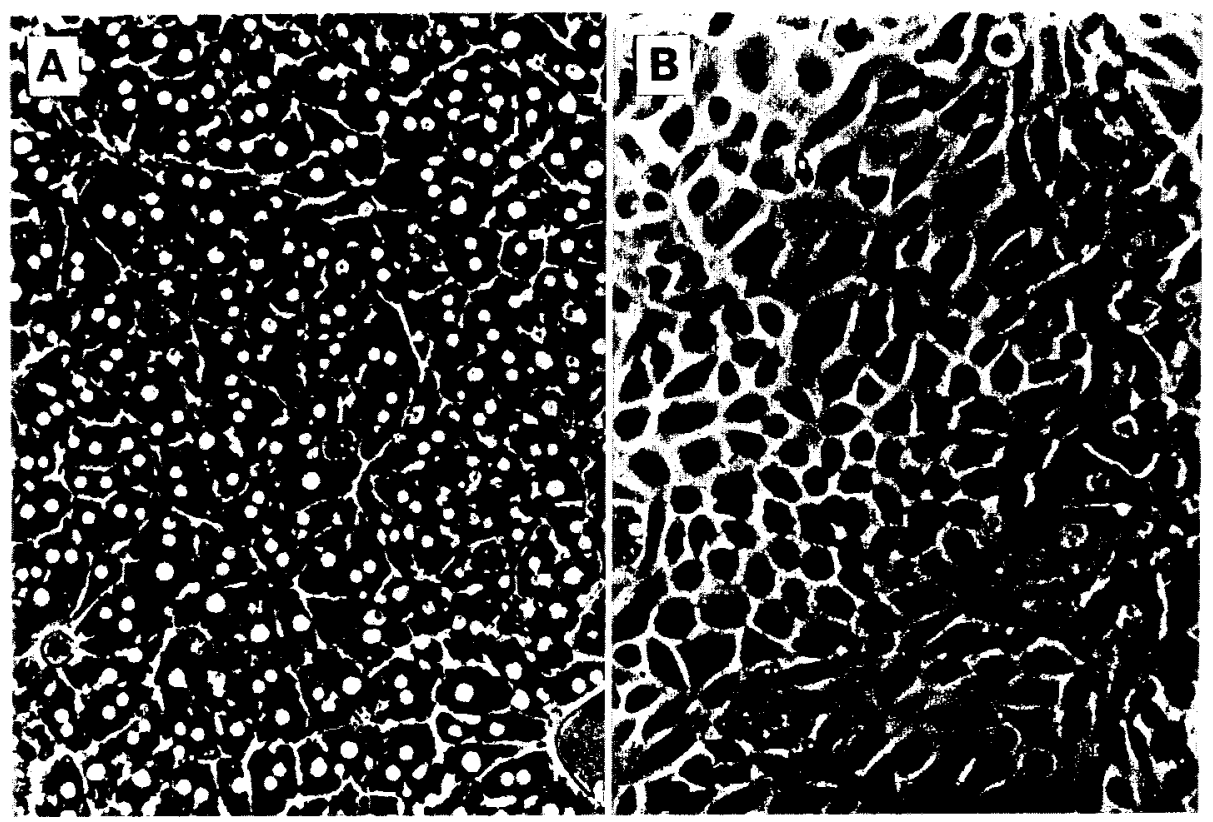

Fig. 1. Phase-contrast microscopic appearance of hepatocytes of adult rats in primary culture. Hepatocytes at confluency were cultured in Williams medium E supplemented with $5 \%$ calf serum and $10^{-9} \mathrm{M}$ dexamethasone for 1 day $(\mathrm{A}, \times 140)$ and 14 days $(\mathrm{B}, \times 210)$.

time. Suitable culture conditions were first reported by Bissell et al. in 1973 (2). Since then there have been many reports showing that this primary culture system is the most suitable for studies on liver functions and hormonal responses in vitro $(2,3,6,9,25,28,30,37)$.

A drawback of these culture conditions has been that mature hepatocytes in primary culture do not proliferate at all, even in the presence of fetal bovine serum, which usually stimulates growth of established cell lines. Therefore, in these culture conditions hepatocytes could survive for only about a week and then became detached from the culture dishes, being replaced by non-parenchymal epithelial cells, which contaminated a few percentage in the original parenchymal cell population and could grow under these conditions (Fig. 1). These epithelial cells do not show any liver functions and so called "established liver cell lines" probably originate from them.

Therefore, not only for culture per se, but also for studies on the mechanisms of liver regeneration and hepatocarcinogenesis, it was important to establish good conditions for growth of primary cultures of hepatocytes that allow the cells to maintain liver functions and hormonal responses. Here we describe recent findings on the growth and functions in primary culture of hepatocytes and discuss their regulatory mechanisms.

\section{Growth regulation of mature hepatocytes}

1. Cell density-dependent regulation of growth. Mature hepatocytes usually re- 
main in the resting phase $\left(G_{0}\right)$ in vivo. However, unlike nerve or muscle cells, hepatocytes can proliferate under certain conditions, such as after partial hepatectomy or liver injury. Therefore, the mechanism of liver regeneration has been studied for many years, but with little success until recently (11).

In primary culture, mature hepatocytes do not grow at all under usual culture conditions, but in 1976 Richman et al. showed that additions of insulin and EGF to the medium induced DNA synthesis (32). This finding has been confirmed by many others including us $(7,10,14,16,27,39)$. Moreover, we noticed that at a high cell density of near confluency $\left(10^{5}\right.$ cells $\left./ \mathrm{cm}^{2}\right)$, DNA synthesis induced by these two hormones was slight in $20 \mathrm{~h}$-culture, but became appreciable in $40 \mathrm{~h}$-culture (39). As shown in Fig. 2, the lag period required for start of DNA synthesis becomes shorter with decrease of cell density (27). This lag period apparently corresponds to the time required for the cells to proceed from the $G_{0}$ phase to the $G_{1}$ phase, in which they respond to insulin and EGF and move to the $S$ phase. This time required for the $\mathrm{G}_{0}-\mathrm{G}_{1}$ shift depends on cell density. Thus at low cell density $\left(3 \times 10^{4} \mathrm{cells} / \mathrm{cm}^{2}\right)$ $70-80 \%$ of the hepatocytes entered the $\mathrm{S}$ phase in the presence of two hormones (Fig. 3A, B) and $36 \mathrm{~h}$ after hormone addition they showed an increase in cell number (Fig. 3C, D). It is interesting that the two nuclei of many binuclear cells seen in adult liver also synthesize DNA synchronously (Fig. 3B). As a result of cell division many mitotic figures can be seen, as shown by phase contrast and fluorescent microscopies of the same cells (Fig. 4). Unlike cells in skin and intestinal epithelium, which proliferate from basement stem cells and then differentiate, mature hepatocytes themselves divide and increase.

These results indicate that the first point of regulation of hepatocyte growth is at the step between the $\mathrm{G}_{0}$ and $\mathrm{G}_{1}$ phases. This point is regulated by cell-cell contact. Most differentiated cells in vivo are supposed to be in the $\mathrm{G}_{0}$ phase, and hence in studies on the mechanisms regulating growth of functional cells or their carcinogenesis, more attention should be paid to this $\mathrm{G}_{0}-\mathrm{G}_{1}$ shift. Moreover, on the basis of these

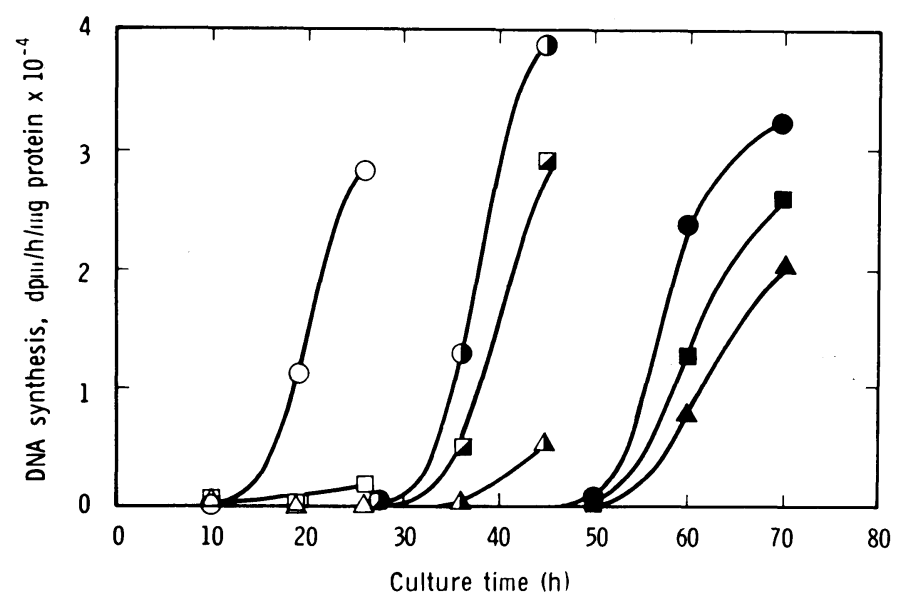

Fig. 2. Density-dependent synthesis of DNA. Hepatocytes at different cell densities (circles, $3 \times 10^{4} / \mathrm{cm}^{2}$; squares, $6 \times 10^{4}$; triangles, $12 \times 10^{4}$ ) were cultured and at $5 \mathrm{~h}$ (open symbols), $20 \mathrm{~h}$ (semiclosed symbols) and $40 \mathrm{~h}$ (closed symbols) insulin $\left(10^{-7} \mathrm{M}\right)$ and EGF $(20 \mathrm{ng} / \mathrm{ml})$ were added. [methyl- ${ }^{3} \mathrm{H}$ ]Thymidine was added $2 \mathrm{~h}$ before assay of DNA synthesis. 


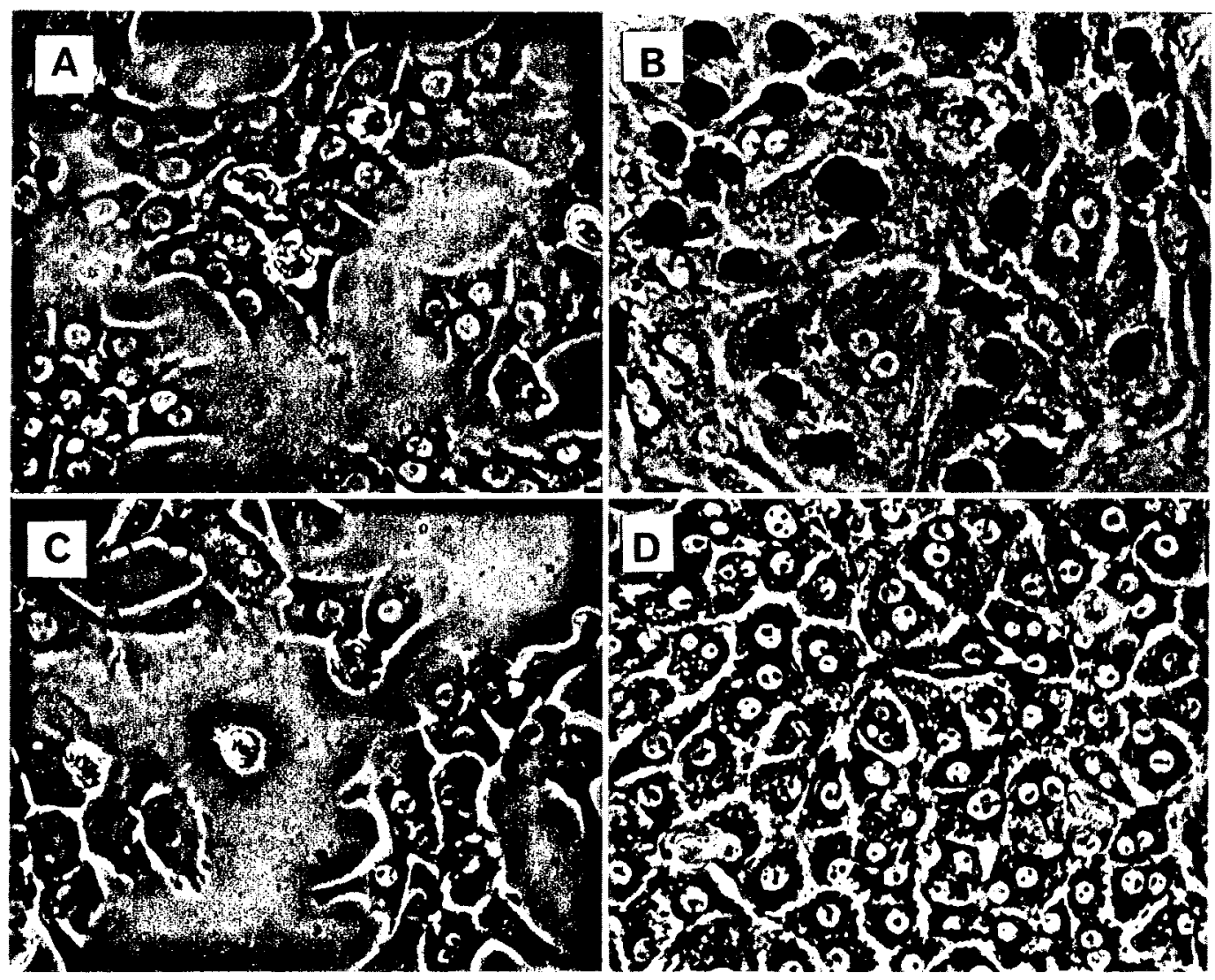

Fig. 3, Increases of DNA synthesis (A, B) and cell number (C, D) of hepatocytes cultured with insulin and EGF at low cell density. Hepatocytes $\left(3 \times 10^{4}\right.$ cells $\left./ \mathrm{cm}^{2}\right)$ were cultured as described in Fig. 2. [methyl- ${ }^{3} \mathrm{H}$ ]Thymidine incorporation was measured by radioautography $24 \mathrm{~h}$ after additions of insulin and EGF (B) or at this time without hormones (A). Phase-contrast microphotographs were also taken $36 \mathrm{~h}$ after hormone addition (D) or at this time without hormones (C). $\times 200$.

considerations, it is clear that established cell lines, which are not in the $\mathrm{G}_{0}$ phase and usually stay in the $G_{1}$ phase even under resting conditions, are not suitable for studies on either normal or abnormal cell growth; primary cultures of mature hepatocytes are the most suitable for such studies.

2. Specific requirement of collagen for hepatocyte proliferation. During studies of suitable culture media for hepatocytes, we noticed that for cell survival Leibovitz L-15 medium (L-15) is better than Williams medium E (WE), which we had usually used. However, hepatocytes in L-15, unlike those in WE, did not synthesize DNA at all even in the presence of insulin and EGF. A survey of other media showed that there were two types of media: Ham F-12, McCoy 5A, Parker 199, RPMI 1640 and WE media were suitable for DNA synthesis, whereas Eagle's MEM, Dulbecco's modified MEM and L-15 were unsuitable for DNA synthesis (Fig. 5). L-15 does not contain four amino acids (Asp, Glu, Cys and Pro) and four metal ions $\left(\mathrm{Cu}^{2+}, \mathrm{Fe}^{2+}\right.$, $\mathrm{Mn}^{2+}$, and $\mathrm{Zn}^{2+}$ ) present in WE. Addition of the four metal ions to $\mathrm{L}-15$ did not promote DNA synthesis in hepatocytes, but of the amino acids that are deficient in 


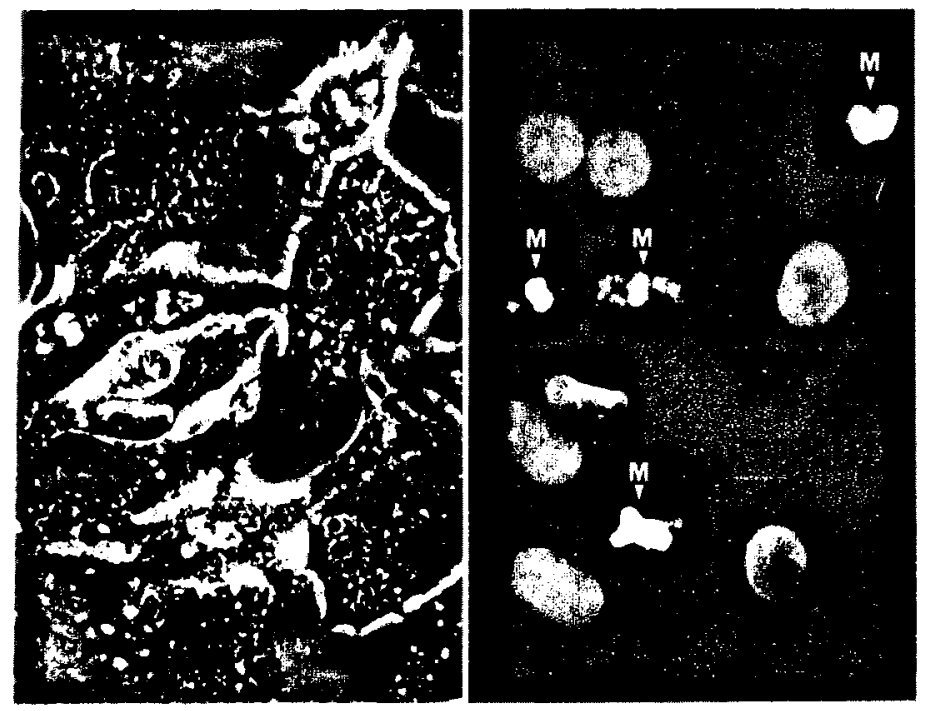

Fig. 4. Mitotic figures of hepatocytes cultured with insulin and EGF. Left: phase-contrast micrograph, right: fluoromicrograph with Hoechst 33258. Cells were treated with the two hormones for $24 \mathrm{~h}$ and TN-16 was added for $6 \mathrm{~h}$ before fixation. Arrows in both panels indicate the same mitotic cells.

L-15, Pro was found to provoke marked DNA synthesis in L-15 in the presence of insulin and EGF (26). The other media that did not support DNA synthesis were also found to lack Pro and when supplemented with Pro they did support DNA synthesis, addition of Pro at $30 \mathrm{mg} / \mathrm{l}$ being most effective (Table 1). Conversely omission of Pro only from WE resulted in loss of its ability to support DNA synthesis and readdition of Pro restored this ability. These results showed that Pro is essential for DNA synthesis in mature hepatocytes.

Then, what is the role of Pro in hepatocyte growth? Pro is a major constituent of collagen, some Pro being specifically hydroxylated in procollagen. Therefore, we examined the effects of inhibitors of collagen synthesis on DNA synthesis in hepatocytes. Addition of cis-4-hydroxy-proline (cis-OH-Pro) to WE or L-15 supplemented with Pro $(30 \mathrm{mg} / \mathrm{l})$ caused dose-dependent inhibition of DNA synthesis (Fig. 6). The inhibition was maximal with cis-OH-Pro at $120 \mu \mathrm{g} / \mathrm{ml}$, which did not show any cytotoxicity or inhibit protein synthesis. The inhibition by cis-OH-Pro was reversible, because addition of 5-fold excess of Pro to WE containing cis-OH-Pro resulted in recovery of ability to support DNA synthesis. Other inhibitors of collagen synthesis, such as $\alpha, a^{\prime}$-dipyridyl and D-penicillamine, which inhibit proline hydroxylase and maturation of collagen fiber, respectively, also inhibited DNA synthesis in hepatocytes dose-dependently. Conversely, ascorbic acid, a stimulator of collagen synthesis, increased DNA synthesis 1.5 times.

These results showed that collagen synthesis in hepatocytes is closely related to their DNA synthesis. It should be mentioned that these results were obtained on hepatocytes cultured on dishes coated with collagen from rat tail, which is type I collagen. Addition of types II and IV collagen to cells cultured in L-15 also did not induce DNA synthesis. These results suggest that a specific type of collagen or its 


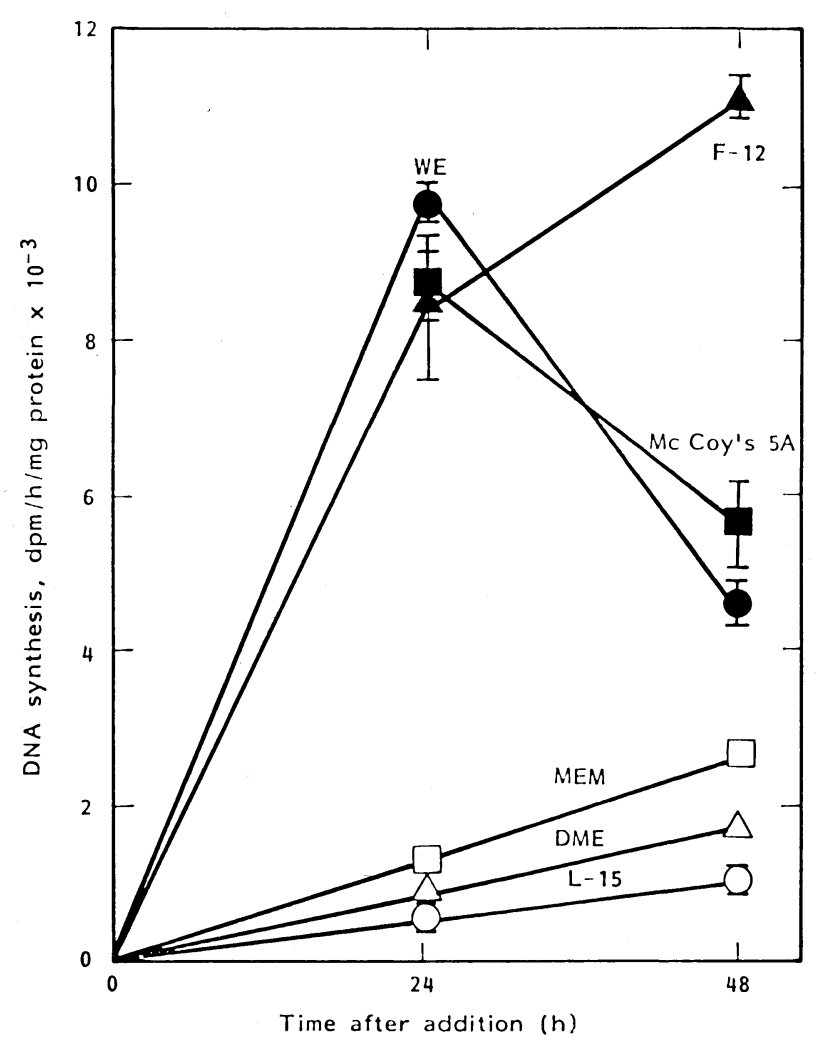

Fig. 5. Effects of various culture media on DNA synthesis. Hepatocytes $\left(5 \times 10^{4} \mathrm{cells} / \mathrm{cm}^{2}\right)$ were cultured in various media and DNA synthesis was measured as described in Fig. 2.

endogenous synthesis is necessary for hepatocyte DNA synthesis.

The mechanism how collagen is involved in hepatocyte DNA synthesis is still unknown. The effect of Pro on DNA synthesis is seen only in the presence of insulin and EGF: Pro alone does not stimulate DNA synthesis. We found that Pro was required to stimulate DNA synthesis in the first $12 \mathrm{~h}$ after insulin and EGF were

TABLE 1. EFFECT OF L-PROLINE ON DNA SYNTHESIS

\begin{tabular}{ccc}
\hline & \multicolumn{2}{c}{$\begin{array}{c}\text { DNA synthesis stimulated by insulin and EGF } \\
\left(\mathrm{dpm} / \mathrm{mg} \text { protein } \times 10^{-4}\right)\end{array}$} \\
\cline { 2 - 3 } Medium & - Pro & + Pro $(30 \mathrm{mg} / \mathrm{l})$ \\
\hline WE & $23.5 \pm 1.71$ & \\
L-15 & $3.2 \pm 1.09$ & $23.7 \pm 2.92$ \\
Eagle's MEM & $4.8 \pm 0.64$ & $16.3 \pm 0.95$ \\
Dulbecco's MEM & $4.0 \pm 0.24$ & $18.7 \pm 1.90$
\end{tabular}

Hepatocytes at low cell density were cultured in various media. Insulin $\left(10^{-7} \mathrm{M}\right)$ and EGF $(20 \mathrm{ng} /$ $\mathrm{ml}$ ) were added to cultures $20 \mathrm{~h}$ after plating and [methyl- ${ }^{3} \mathrm{H}$ ] thymidine was added $14 \mathrm{~h}$ later. DNA synthesis was determined after $34 \mathrm{~h}$. Addition of serum or coating dishes with rat tail collagen did not affect DNA synthesis. 


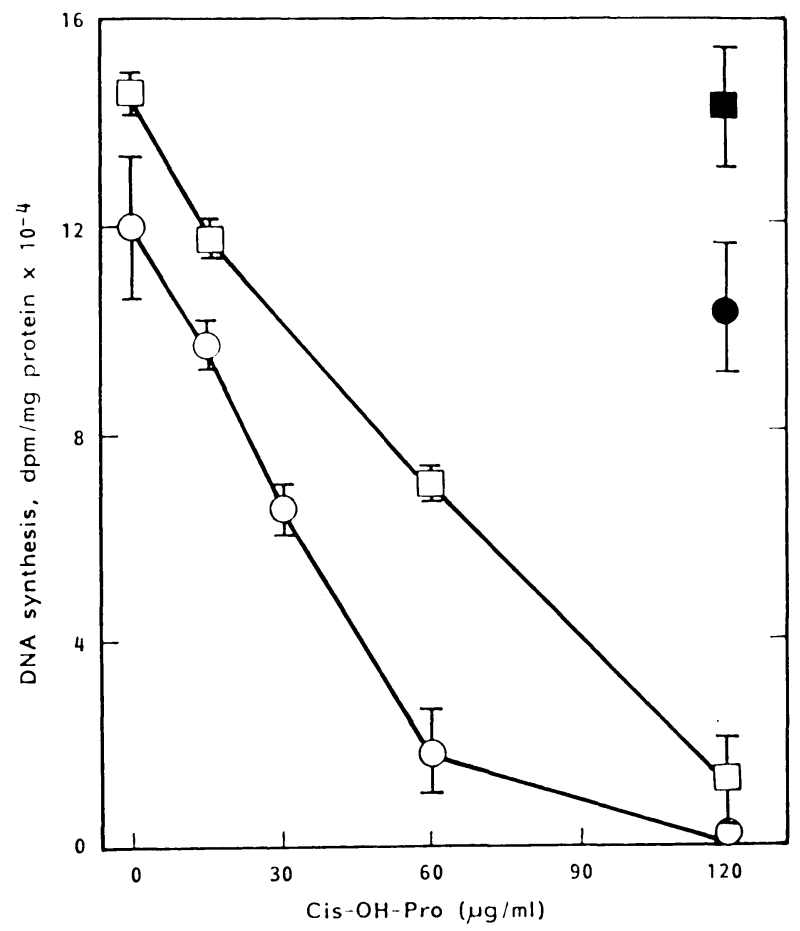

Fig. 6. Inhibitory effect of cis-OH-Pro on DNA synthesis. Hepatocytes were cultured with the inhibitor and DNA synthesis was measured as described in Table 1. Open circles, WE; open squares, L-15 supplemented with L-Pro $(30 \mathrm{mg} / 1)$; closed circles, WE supplemented with L-Pro $(150 \mathrm{mg} / \mathrm{l})$; closed squares, L-15 supplemented with L-Pro $(180 \mathrm{mg} / \mathrm{l})$.

added and addition of cis-OH-Pro after this period showed little effect on DNA synthesis (unpublished), suggesting that collagen is required in the early $G_{1}$ phase, but not in the transitional stage from the $G_{0}$ to $G_{1}$ phase.

Studies on growth of Balb/c 3T3 cells showed that first PDGF makes the cells competent and then insulin, somatomedin and EGF stimulate the cells to proceed to the $\mathrm{S}$ phase $(31,35)$. If a similar mechanism operates in hepatocytes, collagen may act as the factor making the cells competent, and then insulin and EGF may stimulate the hepatocytes to proceed to the $\mathrm{S}$ phase. However, regardless of the mechanism of its action, it is interesting that collagen, which was hitherto thought to be simply a component of connective tissue, plays an important physiological role in DNA synthesis. A similar idea was proposed by Enat et al. (5).

Hepatocytes in primary culture have been shown to synthesize collagen $(4,41)$, which is mainly type III with small amounts of types I and IV (4). Recently, electron microscopic studies on preparations treated with monoclonal antibodies against various types of collagen have shown that type I, III and IV collagens are present between hepatocytes and Disse's space (13). Therefore, hepatocytes in situ are in contact not only with each other, but also with the biomatrix composed of collagen and various glycoproteins, and various activities of hepatocytes must be influenced by this microenvironment. 
In this section we have described the effect of collagen in the biomatrix; the effects of neighboring hepatocytes and a membrane regulatory factor are described in section III-1 and 2. These effects provide an understanding of the molecular mechanism of hepatocyte regulation as a liver tissue.

3. Serum growth factor for hepatocytes (Hepatotropin, HTP). It has been postulated that active liver regeneration induced by partial hepatectomy is stimulated by increase in some growth factor(s) in the serum. This idea was suggested from findings in parabiotic rats (18) and experiments on liver transplantation (12). Since insulin and EGF stimulate growth of hepatocytes in primary culture, it has been thought that these two hormones may be the serum growth factor(s). There is no evidence, however, that the concentrations of these hormones in the serum increase after partial hepatectomy, and on the contrary, the level of insulin was shown to decrease after the operation. Moreover, the finding that the effective concentration of EGF for stimulation of DNA synthesis in hepatocytes in culture is 20-30 fold higher than that in serum adds further doubt to the idea that these hormones are serum growth factors.

Recent reports suggest the existence of a growth factor for hepatocytes in serum that is not EGF or PDGF $(16,36)$. We also found a serum factor that promotes DNA synthesis in hepatocytes in culture in the absence of insulin and EGF (23). The concentration of this factor increased in the serum of rats after partial hepatectomy. We isolated this factor by Sephadex G-200 chromatography, which showed that it had a molecular weight of $150 \mathrm{KD}$. This factor is acid labile and inactivated by heating at $90^{\circ} \mathrm{C}$ for $3 \mathrm{~min}$ and by trypsin treatment, indicating that it is an acid- and heat-labile protein. This serum factor had additive effects with insulin and EGF in stimulating DNA synthesis (Table 2), suggesting that their mechanisms of action are different. We named the serum factor hepatotropin (HTP) (23). In whole serum the effect of HTP was hard to observe, but it could be detected in a fraction of molecular weight $150 \mathrm{KD}$ obtained by gel filtration. In normal rat serum low activity of HTP was detected, but after partial hepatectomy it increased 3-5 times. It increased appreciably $12 \mathrm{~h}$ after the operation, reaching a maximum after $24 \mathrm{~h}$ and then gradually decreasing. In attempts to purify HTP, we found that it was not adsorbed to CM-cellulose at neutral $\mathrm{pH}$, but was adsorbed to DEAE cellulose, suggesting that it is an acidic protein. It could be purified 20 -fold by heparinSepharose CL-6B column chromatography. Some possible growth factors, such as PDGF, FGF, somatomedins, thrombin and transferrin did not have any effect on

TABLE 2. EFFECTS OF HTP, INSULIN AND EGF ON DNA SYNTHESIS AND THE LABELING INDEX

\begin{tabular}{lcc}
\hline \multicolumn{1}{c}{ Hormones } & $\begin{array}{c}\text { DNA synthesis } \\
(\mathrm{dpm} / \mathrm{mg} \text { protein })\end{array}$ & $\begin{array}{c}\text { Labeling index } \\
(\%)\end{array}$ \\
\hline None & $420 \pm 287$ & $1.3 \pm 2.2$ \\
Insulin $\left(\mathrm{I}, 10^{-7} \mathrm{M}\right)+\mathrm{EGF}(20 \mathrm{ng} / \mathrm{ml})$ & $9905 \pm 810$ & $29.6 \pm 5.1$ \\
HTP-A $(2.4 \mathrm{mg} / \mathrm{ml})$ & $8032 \pm 268$ & $27.9 \pm 4.7$ \\
HTP-B $(86 \mu \mathrm{g} / \mathrm{ml})$ & $5239 \pm 309$ & $15.1 \pm 2.2$ \\
HTP-A $+\mathrm{I}+\mathrm{EGF}$ & $16885 \pm 1879$ & $52.3 \pm 4.8$ \\
HTP-B $+\mathrm{I}+\mathrm{EGF}$ & $13883 \pm 1031$ & $44.9 \pm 9.0$
\end{tabular}

Hepatocytes were cultured in WE as described in Table 1, except that DNA synthesis was measured $24 \mathrm{~h}$ after addition of [methyl- ${ }^{3} \mathrm{H}$ ] thymidine. Fraction HTP-A was obtained by Sephadex G-200 chromatography and HTP-B by heparin-Sepharose chromatography. 
DNA synthesis, suggesting that HTP in rat serum is a new growth factor.

Recently, a hepatocyte growth factor that was not identical with PDGF was reported by Bucher's group to be localized in rat platelets (36). This factor was partially purified and found to be a basic, heat-labile protein with a molecular weight of $65 \mathrm{KD}$ (33). Recently, Michalopoulos et al. reported that rat and human sera contain two growth factors for rat hepatocytes in culture (17). One has a molecular weight of over $120 \mathrm{KD}$ is and heat-labile, while the other is less than $3 \mathrm{KD}$ and is heat-stable. Morley and Kingdon also reported the presence of a hepatocyte growth factor in the serum of rats after partial hepatectomy (20). This factor has a molecular weight of $26 \mathrm{KD}$ and is heat-stable. Thus there seem to be several hepatocyte growth factors in the serum. Comparative studies of these growth factors are necessary after their further purification. The origins of these factors are also of interest. Although we could not detect any HTP activity in extracts of platelets or regenerating liver, our recent work suggests that ATP is localized in platelet together with its inhibitor and that the two are secreted sequentially after partial hepatectomy (unpublished data).

\section{Control of growth and functions of hepatocytes by cell-contact; cell sociological consideration}

1. Reciprocal modulation of hepatocyte growth and functions by cell-cell contact. In liver lobules, hepatocytes are arranged radially between the peripheral portal vessels and central veins and are the in contact with each other on one side and with the biomatrix on the other side. This liver microarchitecture with cell contact should controll the hepatocytes, resulting in their expression of fully differentiated characters and suppressing their growth. In this in vivo state, the hepatocytes are in the $\mathrm{G}_{0}$ phase and this state can be reproduced in vitro as described in section II-1. When hepatocytes are cultured at high cell density (confluency), which is about half that in vivo, their DNA synthesis is suppressed and their liver specific, differentiated functions are expressed maximally (Fig. 7 and Table 3). For example, the hormonal inductions of

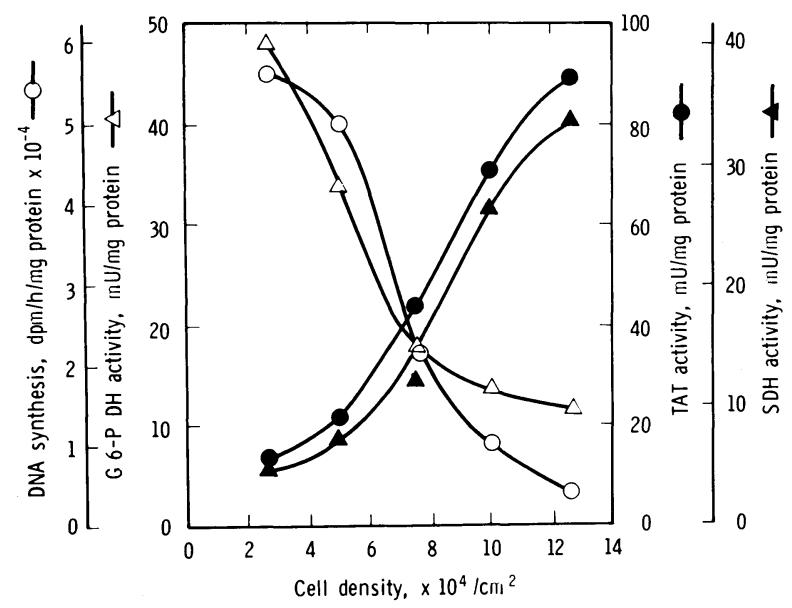

Fig. 7. Reciprocal effects of hepatocyte density on growth-related and differentiated functions. Culture conditions were as described for Table 3. 
TABLE 3. RECIPROCAL EFFECTS OF CELL DENSITY ON GROWTH RELATED AND HEPATOCYTE SPECIFIC FUNCTIONS IN PRIMARY CULTURES

\begin{tabular}{lllrr}
\hline \multirow{2}{*}{ Function } & \multirow{2}{*}{ Stimulators } & \multicolumn{3}{c}{ Activity $(\%)$} \\
\cline { 3 - 5 } & & \multicolumn{2}{c}{ Cell density $\left(\times 10^{4}\right.$ cells $\left./ \mathrm{cm}^{2}\right)$} \\
\hline DNA synthesis & insulin +EGF & 100 & 36 & 12.5 \\
Amino acid transport & insulin & 100 & 67 & 42 \\
Protein synthesis & & 100 & 84 & 52 \\
Cholesterogenesis & & 100 & 75 & 37 \\
G6PD induction & insulin+EGF & 100 & 38 & 23 \\
\hline Triglyceride synthesis & insulin & 33 & 88 & 100 \\
induction of & & & & \\
\multicolumn{1}{c}{ ME } & insulin+triiodothyronine & 34 & 50 & 100 \\
TAT & dexamethasone & 11 & 47 & 100 \\
TO & dexamethasone & 13 & 55 & 100 \\
SDH & dexamethasone+ glucagon & 13 & 44 & 100
\end{tabular}

Hepatocytes were cultured at various cell densities for several hours and then the indicated hormones were added and various cell activities were assayed $24-48 \mathrm{~h}$ later.

tyrosine aminotransferase (TAT), serine dehydratase (SDH) and tryptophan oxygenase (TO), which are related to gluconeogenesis, and hence are liver-specific functions, are maximal at this high cell density, although they are very low at low cell density. In contrast, activities that are related to growth, such as DNA synthesis, amino acid transport, protein synthesis, cholesterogenesis and induction of glucose6-phosphate dehydrogenase (G6PD) are regulated in the opposite way by cell density; namely, they are high at low cell density and low at high cell density. It is interesting to find that of the lipogenesis, cholesterogenesis is regulated by cell growth, while synthesis of triglycerides is regulated by cell differentiation. This difference can be explained by supposing that cholesterogenesis is necessary for membrane biogenesis during cell growth, whereas triglyceride synthesis is accelerated for lipoprotein secretion in mature hepatocytes. Similar opposite regulations of the two enzymes producing NADPH, namely G6PD and malic enzyme (ME), were observed. G6PD may supply NADPH for cholesterogenesis and ribose-5-phosphate for nucleic acid synthesis during cell growth, while ME may supply NADPH and oxaloacetate for fatty acid synthesis in mature hepatocytes. These explanations are supported by the finding that EGF induces G6PD, but suppresses ME (42).

This regulation of hepatocyte differentiation is based on a transcriptional mech-

TABLE 4. EFFECT OF CELL DENSITY ON TRANSCRIPTION OF TO

\begin{tabular}{ccc}
\hline $\begin{array}{c}\text { Cell density } \\
\left(\times 10^{4} / \mathrm{cm}^{2}\right)\end{array}$ & $\begin{array}{c}\text { mRNA activity } \\
(\text { In vitro translation) }\end{array}$ & $\begin{array}{c}\text { Amount of mRNA } \\
\text { (Dot hybridization) }\end{array}$ \\
\hline 3.1 & $0.031^{\mathrm{a}}$ & $18^{\mathrm{b}}$ \\
6.2 & 0.118 & 117 \\
12.5 & 0.222 & 214
\end{tabular}

Hepatocytes were cultured as described for Table 3. a $\%$ of total mRNA. ${ }^{\mathrm{b}}$ Arbritrary densitometric units. 
anism like that for DNA synthesis; we showed that the regulations of SDH and TO by cell density are due to change in mRNA activities of these enzymes. Furthermore, change in the amount of TO mRNA in hepatocytes at low and high density was shown by Northern hybridization with TO cDNA (Table 4). Therefore, these reciprocal modulations of hepatocyte growth and differentiation by cell density are possibly controlled at the gene level.

2. Cell surface modulator $(C S M)$. From the findings mentioned above it is interesting to investigate the mechanism underlying this elaborate reciprocal regulation of growth and functions of hepatocytes. Two possibilities may be considered. One is an autocrine, humoral factor secreted by hepatocytes themselves and the other is a membrane-bound factor through cell-cell contact.

The first possibility was examined by adding conditioned medium from cultures at high cell density to cultures at low cell density and examining the latter for activities related to growth and differentiated functions mimicing those at high cell density. Results showed that conditioned medium had no effect.

The second possibility was examined by adding plasma membranes from liver to hepatocytes cultured at low cell density to see whether these membranes could mimic the effect of high cell density. As shown in Fig. 8, addition of highly purified plasma membranes from rat liver caused dose-dependent suppression of DNA synthesis and induction of TAT activity in hepatocytes cultured at low cell density (29). Addition of plasma membranes also resulted in change in shape of hepatocytes to resemble that of hepatocytes in dense cultures; that is, reduction in cell spreading and formation

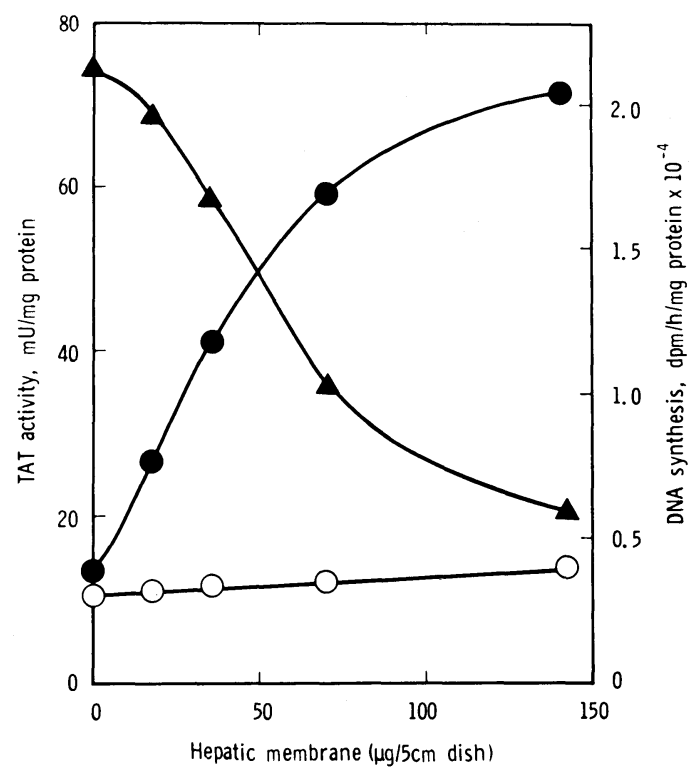

Fig. 8. Effect of addition of hepatic plasma membranes to hepatocytes cultured at low cell density in stimulating TAT induction (circles) and suppressing DNA synthesis (triangles). The membranes were added to cultures $2 \mathrm{~h}$ after cell plating and various hormones were added $22 \mathrm{~h}$ after addition of membranes. TAT induction and DNA synthesis were measured $24 \mathrm{~h}$ after hormone addition. Open circles are values without addition of dexamethasone. 
of small, round cells. The effect of the plasma membranes was inhibited by heating them $\left(95^{\circ} \mathrm{C}\right.$ for $2 \mathrm{~min}$, or $65^{\circ} \mathrm{C}$ for $\left.15 \mathrm{~min}\right)$ or treating them with trypsin $(1 \mu \mathrm{g} / \mathrm{ml}$ for $15 \mathrm{~min}$ ).

These results indicate that the effective factor in the membranes is a heat-labile protein. This factor could not be solubilized from plasma membranes of liver by treatment with ordinary detergents, but was solubilized by their treatment with $4 \%$ octylglucoside plus $4 \mathrm{M}$ guanidine- $\mathrm{HCl}$ (21). This solubilized factor was found to be a protein of $670 \mathrm{KD}$ by Sephacryl S-400 chromatography. When this factor was treated with trypsin, a specific fraction of $200 \mathrm{KD}$ seen on SDS-polyacrylamide gel electrophoresis disappeared with concomitant loss of modulator activity. We named this active protein cell surface modulator (CSM). Since the stimulatory and suppressive activities on differentiated functions and DNA synthesis, respectively, could not be separated during purification or by various treatments, it is likely that they are properties of the same protein. CSM was found in plasma membranes of not only liver, but also kidney, brain and red cells. It is likely, therefore, that specific expression in each type of cells is determined by their genetic factors and SCM only modulates these expressions.

3. Possible mechanism of regulation of liver regeneration by CSM and of hepatocarcinogenesis by loss of CSM response. As described above, hepatocytes in vivo are in tight cell-cell contact in a lobule and CSM on their membranes must give a signal to suppress their growth and stimulate their expression of differentiated characters (Fig. 9). Therefore, the bifunctional character of CSM would be suitable to control specific expression of cells in tissue, in other words it could be called tissurization factor.

When cell-cell contact in liver is disturbed by an injury, such as in viral hepatitis, by partial hepatectomy or on treatment with hepatotoxin, suppression of growth by CSM would be lost and surviving hepatocytes in the $G_{0}$ phase would shift to the $G_{1}$ phase, where various humoral factors, such as insulin, EGF and HTP would stimulate the cells to move on to the $\mathrm{S}$ phase and divide. During this cell cycle, the biomatrix including collagen may be important for their smooth shift. When the hepatocytes have divided

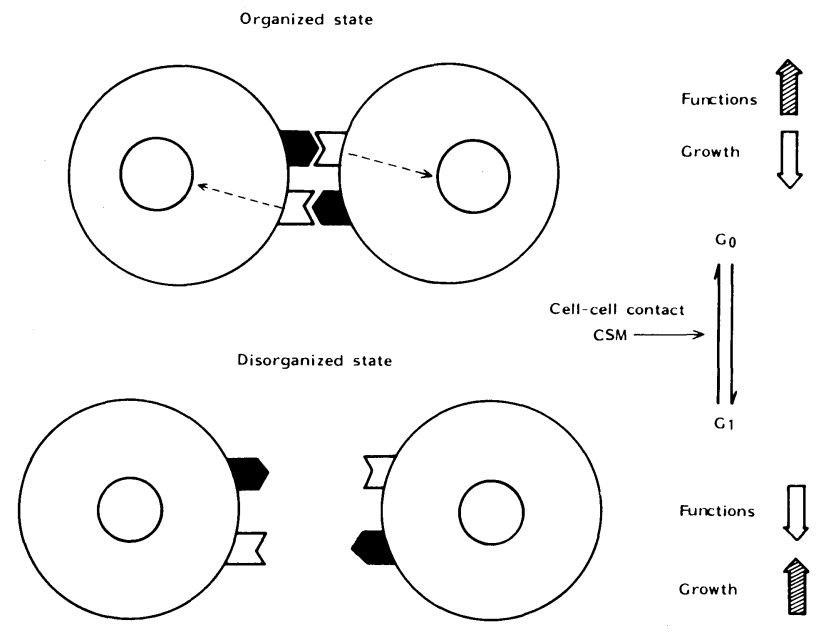

Fig. 9. Possible mechanism of reciprocal regulations of cell growth and functions by SCM. 
once or twice, then cell contact becomes tight again and through CSM regulation the cells go back to the $\mathrm{G}_{0}$ phase, ceasing cell division and expressing specific functions. This is the normal mechanism for wound healing or liver regeneration.

This mechanism may apply not only to hepatocytes, but also to other cell types in liver, such as connective and endothelial cells. If the liver injury is continuous, growth of all cells, particularly fibroblastic cells, would also become continuous and they would become predominant in cell population of the tissue. This would explain the condition in liver cirrhosis due to chronic hepatitis.

The question aries of how this mechanism applies to liver regeneration after partial hepatectomy, in which the remnant tissue seems to retain intact and tight cell contact. But in fact contact of hepatocytes is actually loose, because gap junctions between cells disappear and intercellular communication, such as transfer of small molecules and electric coupling, decreases $(15,38)$. Recently, it was shown that connexon, a protein in gap junctions, disappears after partial hepatectomy with concommitant loss of electric coupling (40). It is also noteworthy that if the cells in the remnant of liver after $70 \%$ partial hepatectomy were to divide only once or twice, their cell number would become that of the original liver.

This control mechanism of growth and functions could also be applied to hepatocarcinogenesis. If the response of hepatocytes to CSM is lost, as discussed above, then they would stay in the cell cycle. In general, cancer cells show loss of intercellular recognition and tissue structure. We examined whether hepatoma cells have lost CSM or the response to CSM using the differentiated Morris and Reuber hepatoma cell lines in culture, $\mathrm{H}_{4}$-II-E and $\mathrm{MH}_{1} \mathrm{C}_{1}$, respectively. These cells retain a few differentiated functions, such as showing induction of TAT by dexamethasone. However, these differentiated functions and DNA synthesis do not show any celldensity dependence, although the plasma membranes of the hepatoma cells retain CSM activity (22), because these membranes can reciprocally modulate DNA synthesis and TAT induction of normal hepatocytes cultured at low cell density. CSM was also found in other cancer cells, such as Morris 7794A, Ehrlich ascites tumor and p-388 leukemia cells. Therefore, loss of regulation by cell-cell contact in tumor cells is not due to loss of CSM, but possibly to loss of the response to CSM of these cells. Whether this loss of a response is due to loss of a CSM receptor or of postreceptor signal transmission is still unknown.

Here, we would like to propose a possible mechanism for the acquisition of autonomous growth and dedifferentiation during hepatocarcinogenesis as loss of CSM modulation at the plasma membrane level, as shown in Fig. 10. By viral infection or carcinogen poisoning, as discussed above, hepatocytes in the $\mathrm{G}_{0}$ phase may enter the cell cycle and at the S phase, DNA could be modified resulting in loss of the response to CSM of the newly divided cells. In this way, cells are immortalized first and further cell division in a carcinogenic environment may cause more commitment of these cells to the carcinogenic state. Recently we induced preneoplastic nodules in rat liver by treatment with diethylnitrosamine and 2-acetylaminofluorene and found that in these lesions expression of TO was totally suppressed while that of G6PD was markedly increased (19). This finding supports the idea that precancerous parenchymal hepatocytes have lost the response to CSM and that their expression of differentiated markers is suppressed, while their proliferation is accelerated.

Recent studies revealed that some oncogenes are closely related with PDGF, EGF and their receptors. If HTP, CSM and their receptors described here are 


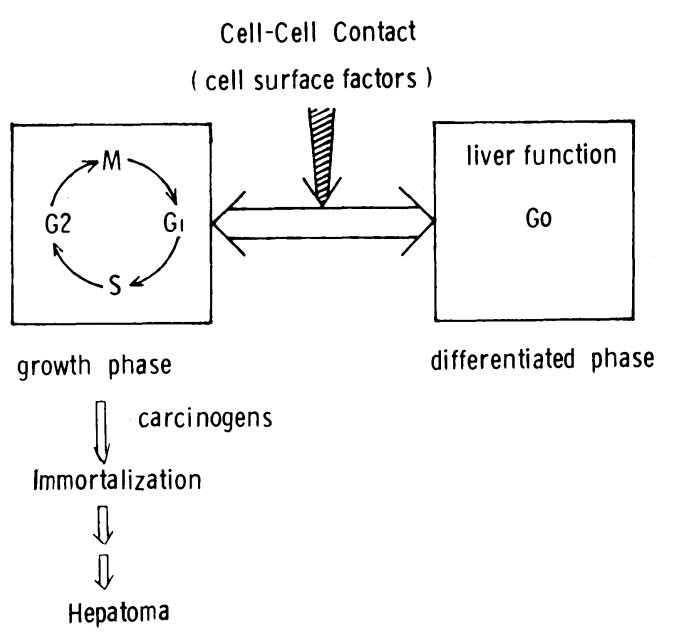

Fig. 10. Possible mechanism of autonomous growth and dedifferentiation of cells during carcinogenesis with special reference to CSM.

related with known or unknown oncogenes, it would be more interesting to understand the mechanism of hepatocarcinogenesis.

\section{Concluding remarks}

In the last ten years many workers have found that primary cultures of mature hepatocytes are the best system for studies on liver functions and hormonal regulation. In addition, recent studies have shown that this system is also very useful for elucidation of the mechanisms of liver regeneration, carcinogenesis, differentiation and tissue formation. These studies have indicated that not only various hormones, but also a membrane factor (CSM) and environmental factor (specific collagen) are very important for hepatocyte growth and functions. That is, hepatocytes do not live by themselves, but are under the control of hormones, neighboring hepatocytes and other cells and the biomatrix. Understanding of liver as an organized tissue, not only in histological, but also in biochemical terms is now just beginning.

Acknowledgment. This work was supported by Grants from the Ministry of Education, Science and Culture of Japan.

\section{REFERENCES}

1. BERRY, M.N. and D.S. FrIEND. High-yield preparation of isolated rat liver parenchymal cells. J. Cell Biol. 42, 506-520, 1969

2. Bissell, D.M., L.H. Hammaker and U.A. Meyer. Parenchymal cells from adult rat liver in nonproliferating monolayer culture. I. Functional studies. J. Cell Biol. 59, 722-734, 1973

3. Bonney, R.J., J.E. Becker, P.R. WAlker and B.R. Potter. Primary monolayer cultures of adult rat liver parenchymal cells suitable for the study of the regulation of enzyme synthesis. In Vitro 9, 399-413, 1974

4. Diegelmann, R.F., P.S. Guzelian, R. Gay and S. Gay. Collagen formation by hepatocytes in primary monolayer culture and in vivo. Science 219, 1343-1345, 1982 
5. Enat, R., D.M. Jefferson, N. Ruiz-Opazo, Z. Gatmaintan, L.A. Leinwand and L.M. Reid. Hepatocyte proliferation in vitro: Its dependence on the use of serum-free hormonally defined medium and substrata of extracellular matrix. Proc. Natl. Acad. Sci. U.S.A. 81, 1141-1415, 1984

6. Guguen-Guillouzo, C. and A. Guillouzo. Modulation of functional activities in cultured rat hepatocytes. Mol. Cell. Biochem. 53/54, 35-56, 1983

7. Hasegawa, K., K. Watanabe and K. Koga. Induction of mitosis in primary cultures of adult rat hepatocytes under serum-free conditions. Biochem. Biophys. Res. Commun. 104, 259-265, 1982

8. ICHIHARA, A. Relation of the characteristics of liver cells during culture, differentiation and carcinogenesis. in Control Mechanisms in Cancer, ed. W.E. Criss, T. Ono and J.R. Sabine, Raven Press, New York, pp. 317-327, 1976

9. IChihara, A., T. NaKamura and K. TANAKA. Use of hepatocytes in primary culture for biochemical studies on liver functions. Mol. Cell. Biochem. 43, 145-160, 1982

10. КосH, K.S. and H.L. LeFFERT. Growth control of differentiated adult rat hepatocytes in primary culture. Ann. N.Y. Acad. Sci. 439, 111-127, 1980

11. LefFert, H.L., K.S. Koch, T. Moran and B. Rubalcava. Hormonal control of rat liver regeneration. Gastroenterology 76, 1470-1482, 1979

12. Leong, G.F., J.W. Grisham, B.Y. Hole and M.L. Albright. Effect of partial hepatectomy on DNA synthesis and mitosis in hepatotropic partial autografts of rat liver. Cancer Res. 24, 1496-1501, 1964

13. Martinez-Hernandes, A. The hepatic extracellular metrix I. Electron immunohistochemical studies in normal rat liver. Lab. Invest. 51, 57-74, 1984

14. McGowan, J.A., A.J. Strain and N.L.R. BuCher. DNA synthesis in primary cultures of adult rat hepatocytes in a defined medium: Effects of epidermal growth factor, insulin, glucagon and cyclic AMP. J. Cell. Physiol. 108, 353-363, 1981

15. MeYer, D.J., S.B. YANCY and J.-P. Revel. Intercellular communication in normal and regenerating rat liver: A quantitative analysis. J. Cell Biol. 91, 505-523, 1981

16. Michalopoulos, G., H.D. Cianciulli, A.R. Novotny, A.D. Kligerman, S.C. Strom and R.L. JiRTLE. Liver regeneration studies with rat hepatocytes in primary culture. Cancer Res. 42, 4673-4682, 1982

17. Michalopoulos, G., K.A. Houck, M.L. Dolan and N.C. Luetteke. Control of hepatocyte replication by two serum factors. Cancer Res. 44, 4414-4419, 1984

18. Moolton, F.L. and N.L.R. Bucher. Regeneration of rat liver: Transfer of hormonal agent by cross circulation. Science 158, 272-274, 1967

19. Moore, N.A., T. Nakamura, N. Ito and A. Ichihara. Stimulation of expression of glucose-6phosphate dehydrogenase and suppression of tryptophan 2,3-dioxygenase in preneoplastic nodules in rat liver. Carcinogenesis, submitted

20. MoRley, C.G.D. and H.S. KINGDON. The regulation of cell growth I. Identification and partial characterization of a DNA synthesis stimulating factor from the serum of partially hepatectomized rats. Biochim. Biophys. Acta 308, 260-275, 1973

21. Nakamura, T., Y. Nakayama and A. Ichihara. Reciprocal modulation of growth and liver functions of mature rat hepatocytes in primary culture by an extract of hepatic plasma membranes. J. Biol. Chem. 259, 8056-8058, 1984

22. Nakamura, T., Y. Nakayama, H. Teramoto, K. Nawa and A. Ichihara. Loss of reciprocal modulations of growth and liver function of hepatoma cells in culture by contact with cells and cell membranes. Proc. Natl. Acad. Sci. U.S.A. 81, 6398-6402, 1984

23. Nakamura, T., K. Nawa and A. Ichihara. Partial purification and characterization of hepatocyte growth factor from serum of hepatectomized rats. Biochem. Biophys. Res. Commun. 122, 1450-1459, 1984

24. Nakamura, T., C. Noda and A. Ichihara. Control of amount of mRNA for tryptophan 2,3-dioxygenase by hepatocyte density in primary cultures revealed by the hybridization technique with cDNA of the enzyme. manuscript in preparation

25. Nakamura, T., H. Shinno and A. Ichihara. Insulin and glucagon as a new regulator system for tryptophan oxygenase activity demonstrated in primary cultured rat hepatocytes. J. Biol. 
Chem. 255, 7533-7535, 1980

26. Nakamura, T., H. Teramoto, Y. Tomita and A. Ichihara. L-Proline is an essential amino acid for hepatocyte growth in culture. Biochem. Biophys. Res. Commun. 122, 884-891, 1984

27. Nakamura, T., Y. Tomita and A. Ichihara. Density-dependent growth control of adult rat hepatocytes in primary culture. J. Biochem. 94, 1029-1035, 1983

28. Nakamura, T., A. Tomomura, A., C. Noda, M. Shimoji and A. Ichihara. Acquisition of $\beta$-adrenergic response by adult rat hepatocytes during primary culture. J. Biol. Chem. 258 , 9283-9289, 1983

29. Nakamura, T., K. Yoshimoto, Y. Nakayama, Y. Tomita and A. Ichihara. Reciprocal modulation of growth and differentiated functions of mature rat hepatocytes in primary culture by cell-cell contact and cell membranes. Proc. Natl. Acad. Sci. U.S.A. 80, 7229-7233, 1983

30. Noda, C., T. NAKamura and A. Ichihara. $a$-Adrenergic regulation of enzymes of amino acid metabolism in primary cultures of adult rat hepatocytes. J. Biol. Chem. 258, 1520-1525, 1983

31. Pledger, W.J., C.D. Stiles, H.W. Antoniades and C.D. Scher. An ordered sequence of events is required before Balb/c-3T3 cells become committed to DNA synthesis. Proc. Natl. Acad. Sci. U.S.A. 75, 2839-2843, 1978

32. Richman, R.A., T.H. Claus, S.S. Pilkis and D.L. Friedman. Hormonal stimulation of DNA synthesis in primary cultures of adult rat hepatocytes. Proc. Natl. Acad. Sci. U.S.A. 73, 35893593, 1976

33. Russell, W.E., J.A. McGowan and N.L.R. Bucher. Partial characterization of a hepatocyte growth factor from rat platelets. J. Cell. Physiol. 119, 183-192, 1984

34. Seglen, P.O. Preparation of isolated rat liver cells. Methods Cell Biol. 13, 29-83, 1976

35. Stiles, C.D., G.T. Capone, C.D. Scher, H.W. Antoniades, K.J. Wyk and W.J. Pledger. Dual control of cell growth by somatomedins and platelet derived growth factor. Proc. Natl. Acad. Sci. U.S.A. 76, 1279-1283, 1979

36. Strain, A., J.A. McGowan and N.L.R. Bucher. Stimulation of DNA synthesis in primary cultures of adult rat hepatocytes by rat platelet-associated substance(s). In Vitro 18, 108-116, 1982

37. Tanaka, K., M. Sato, Y. Tomita and A. Ichihara. Biochemical studies on liver functions in primary cultures of adult rat hepatocytes I. Hormonal effects on cell viability and protein synthesis. J. Biochem. 84, 937-946, 1978

38. TeE, A. and J.-P. ReVel. Loss and reappearance of gap junctions in regenerating liver. J. Cell Biol. 78, 554-564, 1978

39. Tomita, Y., T. Nakamura and A. Ichihara. Control of DNA synthesis and ornithine decarboxylase activity by hormones and amino acids in primary cultures of adult rat hepatocytes. Exp. Cell Res. 135, 363-371, 1981

40. Trab, O., P.M. Drüge and W. Willecke. Degradation and resynthesis of gap junction protein in plasma membranes of regenerating liver after partial hepatectomy or cholestasis. Proc. Natl. Acad. Sci. U.S.A. 80, 755-759, 1983

41. Tseng, S.C.G., P.C. Lee, P.F. Ells, D.M. Bissell, E.A. Smuckler and R. Stern. Collagen production by rat hepatocytes and sinusoidal cells in primary monolayer culture. Hepatology 2, 13-18, 1982

42. Yoshimoto, K., T. Nakamura and A. Ichinara. Reciprocal effects of epidermal growth factor on key lipogenic enzymes in primary cultures of adult rat hepatocytes: Induction of glucose-6phosphate dehydrogenase and suppression of malic enzyme and lipogenesis. J. Biol. Chem. 258, 12355-12360, 1983 